\title{
Territorios que hablan. Comunicación y resistencias en el norte de Argentina
}

\author{
Speaking territories. Communication and resistances \\ in the north of Argentina
}

\author{
Territórios que falam. Comunicação e resistências \\ no norte da Argentina
}

\section{Mariana Ortega*}

\begin{abstract}
RESUMEN
Los pueblos originarios del norte de Salta se enfrentan cotidianamente a problemáticas sociales y ambientales derivadas de históricos procesos extractivistas. La pobreza, la desnutrición, el racismo y el despojo territorial son condiciones que describen el contexto de vida de las poblaciones originarias. Las políticas y medidas adoptadas por el gobierno de Mauricio Macri a favor de la expansión de la frontera agropecuaria y del crecimiento de la productividad agrícola generaron la multiplicación de conflictos y resistencias en torno a la propiedad y utilización de los territorios. En ese marco, un conjunto de comunidades indígenas se congregó alrededor de la comunicación radial para resistir y poner en tensión tanto la concepción comercial de la tierra, como el uso y depredación de la naturaleza.
\end{abstract}

\begin{abstract}
The native peoples of northern Salta face daily social and environmental problems derived from historical extractive processes. Poverty, malnutrition, racism, and territorial dispossession are conditions that describe the context of native populations' life. Mauricio Macri's government's policies and measures in favor of expanding the agricultural frontier and the growth of agricultural
\end{abstract}

Palabras clave: resistencias, comunicación, extractivismo.

Keywords: resistance, communication, and extractivism.

\footnotetext{
* Argentina. Licenciada en Comunicación Social. Instituto de Investigación en Ciencias Sociales y Humanidades (ICSOH)/Consejo Nacional de Investigaciones Científicas y Técnicas de Argentina (CONICET), Universidad Nacional de Salta, Sede Regional Tartagal, Argentina.E-mail: marortega.012@gmail.com
} 
productivity have generated a multiplication of conflicts and resistance around the ownership and use of territories. Within this framework, a group of indigenous communities gathered around radio communication to resist and tension the commercial conception of land, use, and depredation of nature.

\section{RESUMO}

Os povos nativos do norte de Salta enfrentam diariamente proPalavras-chave: blemas sociais e ambientais derivados de históricos processos resistências, extrativistas. A pobreza, a desnutrição, o racismo e a despossescomunicação e são territorial são condições que descrevem o contexto de vida extrativismo. das populações nativas. As políticas e medidas adotadas pelo governo de Mauricio Macri em favor da expansão da fronteira agropecuária e do crescimento da produtividade agrícola geraram a multiplicação de conflitos e resistências em torno da propriedade e da utilização dos territórios. Neste contexto, um grupo de comunidades indígenas se reuniu em torno da comunicação via rádio para resistir e colocar sob tensão a concepção comercial da terra, o uso e a depredação da natureza. 


\section{Introducción}

En Argentina, a fines de 2015 asumió el gobierno de Mauricio Macri, tras doce años de gobiernos peronistas. Este hecho significó el viraje hacia una nueva forma de entender al Estado, a la vez que dio paso a la puesta en marcha de una serie de acciones denominadas "modernizantes".

Para Vommaro y Gené (2017) la gestión de la alianza CAMBIEMOS constituyó un "proyecto con tonalidades refundacionales, sustentado en una visión de modernización gerencial de la política y el Estado y de desregulación económica controlada" (p. 233). En este sentido, el gobierno de la vida social fue depositario de acciones promotoras de la competencia y el mérito, con fuerte énfasis en la "necesidad de imponer la meritocracia como grilla de inteligibilidad de las relaciones sociales" (Szlechter, Vanegas y Tijonchuk, 2018).

En este contexto, con el criterio refundacional y modernizante por delante, el gobierno fue configurando un escenario de actores aliados y enemigos. Los pueblos originarios, históricamente resistentes al despojo de sus territorios y a las acciones tendientes a la eliminación de sus lenguas nativas y culturas, se transformaron rápidamente en un obstáculo para la implementación del proyecto económico macrista, siendo en consecuencia, actores mayoritariamente disidentes.

Declaraciones públicas del por entonces presidente — quien, por ejemplo, en oportunidad del Foro Económico Mundial de Davos afirmó "todos los sudamericanos son descendientes de europeos" (Los Andes, 2018), al igual que el ex Ministro de Educación Esteban Bullrich y su conocida expresión “Esta es la nueva Campaña del Desierto, pero no con la espada sino con la educación" (La Nación, 2016) — son afirmaciones que valoran positivamente la idea del triunfo "blanco" sobre los pueblos indígenas, origen de la Argentina "civilizada".

Este tipo de declaraciones fueron acompañadas de una serie de acciones concretas desplegadas en torno al recrudecimiento colonial de la idea "guerra contra el indio", cuya máxima expresión durante el gobierno macrista fue el caso de Santiago Maldonado y la oleada de estrategias dispuestas a la demonización del pueblo Mapuche y al desprestigio de sus causas. Alegatos como la supuesta nacionalidad chilena, los vínculos con otros países como Inglaterra, la violencia y 
el separatismo, buscaron construir una imagen negativa y demoniaca de los mapuches y de los pueblos originarios, en consonancia con el pensamiento eurocéntrico del gobierno de CAMBIEMOS.

La creencia, fuertemente enraizada en Buenos Aires y otras grandes provincias como Santa Fe y Córdoba, que entiende que la población argentina se conforma mayoritariamente por descendientes europeos, nos lleva a plantear inquietudes acerca de la presencia de pueblos originarios, su existencia contemporánea y la relación con la historia.

La reflexión de este artículo se centra en los procesos de resistencia de pueblos originarios del noroeste de Argentina durante el período 2016-2019, específicamente en la zona periurbana de la localidad de Tartagal, al norte de Salta. El extractivismo y las diferentes formas de sometimiento implementadas tanto por actores estatales como por privados, han encontrado acciones de resistencia, que en los territorios por analizar combinan componentes de comunicación y procesos de litigio judicial contra la tala, el desmonte y la contaminación ambiental.

\section{Enfoque metodológico}

Este artículo se asienta metodológicamente en los principios propuestos por los estudios de gubernamentalidad, inaugurados a partir de los aportes de Michel Foucault (2000). El análisis de los modos en que los sujetos son conducidos, cómo se conducen a sí mismos y cómo se entretejen relaciones heterogéneas entre gobernantes y gobernados constituyen indagaciones nodales para esta perspectiva. De modo particular, nos interesa retomar la relación entre gobierno y resistencia en el caso de la organización de mujeres indígenas denominada Asociación Regional de Trabajadores en Desarrollo (en adelante ARETEDE).

Los estudios de la gubernamentalidad ocupan un lugar importante en las indagaciones actuales de las ciencias sociales, donde podemos mencionar las investigaciones de Avellaneda (2015), Grondona (2009; 2019), Rose (2007), Rose, O'Malley y Valverde (2012) y Ruidrejo (2019). De igual modo se relevan los aportes de Paulizzi y Milana (2015) acerca de las políticas estatales y la gestión de la pobreza en el norte de Salta, como así también el análisis realizado por Paulizzi (2013; 2015; 2016) en relación con el caso de la Unión de Trabajadores Desocupados de 
Mosconi, que retoma la perspectiva de la gubernamentalidad para dar cuenta de las formas de conducción estatales y las estrategias colectivas de resistencia. Chris Shore (2010) emplea la metodología de la gubernamentalidad para el estudio de las políticas públicas, sus efectos sobre los territorios y la formación de subjetividades.

La relación de la teoría foucaulteana de la gubernamentalidad con la antropología, y en particular, con el método etnográfico, es creciente. Los aportes de Das y Pool (2008) para pensar una antropología de los márgenes estatales recupera la etnografía como vía de indagación del Estado y sus efectos en poblaciones históricamente entendidas "por fuera" de los alcances estatales; asimismo, lo que Inda (2005) denomina "antropologías foucaulteanas de la modernidad" (p. 12) es una contribución que intersecta la trama relacional entre la perspectiva de la gubernamentalidad, la colonialidad y la antropología.

Para Inda (2005) la gubernamentalidad foucaulteana entendida desde la etnografía permite analizar empíricamente los efectos de las racionalidades y técnicas de gobierno, como así también, la formación de subjetividades específicas. Este autor considera que la perspectiva de la gubernamentalidad se focaliza en "el gobierno como un campo heterogéneo de pensamientos y acciones" (p. 7), compuesto por múltiples actores, autoridades, conocimientos, estrategias y dispositivos dispuestos a gobernar las conductas con propósitos específicos.

Por su parte, las contribuciones de Scott (2005) aplican la perspectiva gubernamental a la cuestión del poder colonial y el colonialismo, buscando comprender los fenómenos coloniales, la idea de raza, identidades y sujetos racializados desde lógicas heterogéneas y situadas que se alejen de configuraciones universalistas.

Foucault (1988) plantea entender la resistencia como punto de partida para estudiar las relaciones de poder, analizando sus nodos de aplicación, métodos e inscripciones. En ese sentido, el estudio de una experiencia de resistencia permite dilucidar las construcciones, estrategias desplegadas y las oposiciones y enemigos a los cuales se enfrentan.

Puntualmente, siguiendo la perspectiva foucaultena, partimos de la consideración de las experiencias desde la eventualización, es decir, entendiendo los fenómenos en su carácter de singularidad, esto es, re- 
chazando los universales. De este modo, el proceso de investigación se situó en el campo de las prácticas, definidas por Foucault (1982) como el punto de unión entre lo que se dice y lo que se hace.

Para el análisis de las relaciones y estrategias desplegadas por el colectivo nos valimos de la etnografía, en tanto es una forma de inserción en la vida cotidiana de la organización, escuchando y participando de sus tareas y acciones. También utilizamos técnicas de las investigaciones cualitativas, como las entrevistas en profundidad y las historias de vida.

Por otro lado, para el estudio del medio de comunicación, utilizamos el análisis de contenido cualitativo, pues se trata de una herramienta para la interpretación de diferentes tipos de textos, como transcripciones de audios o videos (Marradi, Archenti y Piovani, 2007). Esta técnica procura dar marcos interpretativos al contenido de los textos, para los efectos de comprender la complejidad de las narraciones en contextos determinados.

\section{Contexto del estudio}

La ciudad de Tartagal es el principal centro urbano del departamento San Martín y se encuentra ubicada al noroeste de la provincia de Salta, en el área de frontera con el Estado Plurinacional de Bolivia, más precisamente a $57 \mathrm{~km}$. del límite entre las ciudades de Salvador Mazza (Argentina) y Yacuiba (Bolivia). La población de Tartagal asciende a 64.530 habitantes, según el último censo realizado en 2010.

La composición demográfica de Tartagal remite a la convivencia entre numerosos pueblos indígenas, junto con grupos migrantes provenientes de los países limítrofes, y también familias de orígenes árabe y griego, quienes fueron los primeros colonos de los territorios. El escenario donde se desarrolla la vida se encuentra atravesado por las fronteras interétnicas que tejen los distintos grupos y que se evidencia en la tajante clasificación de identidades culturales que existe, entre las que es posible mencionar: indígenas, criollos, blancos, bolivianos y paraguayos.

La privatización de los Yacimientos Petrolíferos Fiscales (YPF) a principios de 1990 es uno de los hitos clave que explican la crisis económica y social que vive la zona en la actualidad. Las protestas pique- 
teras desarrolladas entre 1997 y 2001 contra el desempleo, la precariedad de los servicios de salud y educación y la falta de inversión en obras públicas, entre otras causas, desembocaron en la formación de una de las experiencias obreras más conocidas de los últimos tiempos: la Unión de Trabajadores Desocupados de Mosconi (UTD) (Benclowicz, 2009b; Korol, 2006; Svampa, 2003).

Los pueblos originarios que habitan la ciudad de Tartagal y el departamento San Martín pertenecen a la clasificación antropológica "pueblos chaquenses" históricamente pobladores de la macro región denominada Gran Chaco Americano. Particularmente, la zona en estudio está poblada por grupos Wichi, Guaraní, Toba Qom, Chorote, Tapiete, Chulupi o Nivaclé y Chané (Buliubasich y González, 2009). Estos pueblos han subsistido y desarrollado sus vidas a partir de prácticas de caza, recolección de frutos del monte, siembra y pesca, entre otras actividades, diferenciadas de acuerdo al pueblo y dependiendo de los flujos migratorios.

La conquista de estos territorios se remonta a mediados del siglo XIX, con los intentos de control del Chaco, aunque puntualmente, el dominio de los poblados comprendidos entre el departamento San Martín y la localidad de Santa Victoria Este, tuvo lugar de manera muy tardía, es decir, a principios del siglo XX, cuando finalizaron las batallas entre indígenas y militares aproximadamente en 1917 (Kantor, 2012).

Las historias escritas acerca de Tartagal (Pojasi, 2013; Rioja, 1997) refieren a la creación de la ciudad como triunfo del proyecto civilizatorio. La reducción de las poblaciones indígenas al dominio estatal - con la creación formal de la ciudad en 1924, fecha de establecimiento de la primera comisión municipal-, dio paso a un proceso de paulatino sometimiento realizado principalmente a través de la incorporación de los indígenas como mano de obra esclava para los emprendimientos azucareros y madereros (Ceriani Cernadas, 2015; Iñigo Carreras, 1984; 2010; Montani, 2015; Rutledge, 1987) y de la consolidación de la zona como economía de enclave petrolero (Benclowicz, 2009a), lo que habilitó el sistemático despojo territorial.

El crecimiento de la ciudad significó el arrinconamiento de las comunidades indígenas a los suburbios del nuevo orden urbano, en donde viven en la actualidad, con poco espacio para el desarrollo de actividades como la agricultura, y sin monte para la caza ni la recolección. 
La depredación de la naturaleza, a través de la extracción de petróleo, gas, madera y de la siembra intensiva de soja y otros monocultivos, han sido el impulso material para la consolidación del Estado argentino sobre los territorios del norte de Salta, bajo la forma de la desposesión y sometimiento de los pueblos indígenas y la apropiación de territorios por parte del Estado y/o terratenientes.

Como consecuencia de lo anterior, la situación demográfica de la ciudad de Tartagal presenta indicadores que evidencian las precarias condiciones de vida de gran parte de su población. De acuerdo con el último estudio realizado por el gobierno de la provincia de Salta, mediante la encuesta para el Plan Estratégico de Desarrollo Local del Municipio de Tartagal (Operti, 2014), algunos aspectos son alarmantes, como la posesión de la tierra, la infraestructura, los servicios públicos y el hacinamiento. El 25\% de los barrios de la ciudad son asentamientos o villas, es decir, presentan irregularidades en cuanto a la propiedad. En el espacio periurbano o rural, el $30 \%$ de los hogares son ranchos o viviendas muy precarias, en especial, de comunidades indígenas.

Puntualmente, la situación de las poblaciones indígenas de Tartagal se ve afectada por numerosos componentes devenidos de una causa principal: la desposesión territorial. De acuerdo con un estudio realizado por investigadoras de la Universidad Nacional de Salta (Buliubasich y González, 2009) el 86\% de las comunidades originarias de las ciudades del departamento San Martín no posee títulos de los territorios que habitan; la misma investigación señala:

Todas estas comunidades disponen de tierras solo para viviendas, sin posibilidades de contar con terrenos aptos para la realización de actividades de subsistencia tradicionales como la agricultura, caza, recolección, etc. A la vez se encuentran privados de otras alternativas económicas que garanticen la reproducción de la vida en condiciones dignas, ya que la inserción en el mercado laboral es marginal desde el punto de vista de la remuneración y la estabilidad. De esta manera va conformando un amplio cinturón de pobreza en el que se sufre una doble discriminación: económica y étnica. (Naharro, Flores Klaric y Kantor, 2009, p. 59).

A pesar de las políticas sociales adoptadas por los gobiernos kirchneristas, y la sanción de la Ley de Ordenamiento Territorial 26.160, la 
cual buscaba promover la solución de la emergencia territorial de los pueblos indígenas, las condiciones de vida de estas poblaciones continúan siendo precarias. Estas problemáticas de larga data eclosionaron durante los últimos años, ocasionando que a principios de $2020 \mathrm{el}$ gobierno de la provincia de Salta, mediante el Decreto de Necesidad y Urgencia $\mathrm{N}^{\circ} 140$, declarara la emergencia sociosanitaria en los departamentos San Martín, Orán y Rivadavia Banda Norte.

A través de este artículo buscamos reflexionar respecto de las prácticas de resistencia indígena desarrolladas por el colectivo ARETEDE y FM Radio Comunitaria La Voz Indígena en el período 2015-2019.

\section{La comunicación comunitaria y su importancia en las luchas de los pueblos indígenas}

La comunicación estuvo presente en las luchas de pueblos indígenas desde mediados de 1940 aproximadamente, con las primeras experiencias de comunicación popular, puntualmente con el caso de las radios minero-sindicales de Bolivia (Herrera Miller, 2006). Aunque se reconoce este antecedente como pionero en la relación con los medios de comunicación y pueblos originarios, recién en 1980 se evidencia el proceso de emergencia de la comunicación indígena como demanda y apropiación específica (Doyle, 2013).

El campo de la Comunicación Comunitaria, Alternativa o Popular (CCAP) reunió a muchas experiencias de medios indígenas. El impulso transformador de los medios comunitarios y sus características de gestión colectiva, horizontalidad y participación en el marco de un proyecto político de transformación social, fueron los aspectos fundamentales sobre los cuales muchos pueblos originarios edificaron sus proyectos comunicacionales.

La diversidad del campo de estudios de la CCAP se hace visible en la heterogeneidad de respuestas a la pregunta "¿qué es un medio comunitario?”. Al respecto, algunas definiciones intentan resaltar puntos en común que permiten consensuar un concepto. De este modo, Vinelli (2014) destaca que la CCAP es un fenómeno caracterizado por el posicionamiento político a favor de los intereses de clase de los sectores desfavorecidos y que constituye un proyecto contra-hegemónico basado en la recuperación de la palabra. 
La historia de la CCAP y los devenires de conceptos e influencias derivaron en cambios de denominaciones que oscilan entre Comunicación Comunitaria, Popular, Comunicación para el Cambio Social, entre otras, surgidas en diferentes momentos históricos y con acentuaciones específicas (Barranquero y Sáez, 2015; Gumucio Dagrón y Tufte, 2008) En consecuencia, hoy se reconoce que una de las condiciones distintivas de este tipo de medios es justamente la multiplicidad de actores, voces y experiencias colectivas. En ese sentido, Mata (2011) afirma:

Las prácticas de comunicación popular, más allá de sus diferentes orígenes y perspectivas e incluso más allá de sus limitaciones, constituyen uno de los tantos modos que distintos colectivos, instituciones, organizaciones y movimientos desarrollan para cambiar las lógicas del poder que son también las lógicas de la comunicación hegemónica. Permitir que se escuchen voces silenciadas, intentar poner en agenda temas y problemas que otros medios de comunicación ocultan o soslayan, alentar expresiones culturales que el mercado desecha porque no son rentables, son algunas manifestaciones de esa búsqueda. (p. 17).

Los estudios referentes a la comunicación indígena, como categoría específica, recogen análisis que destacan su relación con la comunicación comunitaria, alternativa o popular (Agurto y Mercco, 2012; Lizondo, 2018), como así también lecturas que marcan tensiones entre esta última y la comunicación indígena, aduciendo argumentos que proponen recuperar las cosmovisiones originarias, las formas de comunicación ancestrales y la identidad étnica como principios fundamentales de diferenciación (Baraldini et al., 2009).

Por otra parte, la filosofía del buen vivir y las reflexiones de los ecologismos influencian las conceptualizaciones actuales referentes a la comunicación indígena. La relación de los pueblos originarios con la naturaleza, sus modos y cosmovisiones, las discusiones en torno a la decolonialidad y la búsqueda de nuevas categorías que den cuenta de la diversidad del pensamiento latinoamericano crítico, forman parte de las indagaciones del campo de la comunicación indígena en el presente (Arcila Calderón, Barranquero y González Tanco, 2018; Barranquero y Sáez, 2015; Herrera Huérfano, Sierra Caballero y Del Valle Rojas, 2016). 
La comunicación, ya sea en la categoría CCAP o bajo las conceptualizaciones que apuestan por la identidad étnica como principio de definición, es uno de los principales campos de acción de los pueblos originarios. A través de numerosos formatos y estrategias, la comunicación ha contribuido a la visibilización y presencia de las causas indígenas en las agendas nacionales e internacionales de Latinoamérica.

En Argentina, la sanción en 2009 de la Ley de Servicios de Comunicación Audiovisual 26.522, fue impulsada por organizaciones indígenas y pueblos originarios, que lograron el reconocimiento del derecho a la comunicación indígena dentro de la mencionada norma. Este hecho proyectó una serie de políticas nacionales, implementadas desde 2010 en adelante con el título "Comunicación con Identidad", las cuales tuvieron como objetivo la promoción del acceso al derecho a la comunicación para los pueblos originarios.

Específicamente, la radio La Voz Indígena se constituyó en 2002 como un proyecto comunicacional y en 2008 como un medio comunitario, creado con el propósito de contribuir a la transformación de la historia de sometimientos de los pueblos indígenas de Tartagal y el departamento San Martín. Con esa meta, la construcción del medio contribuyó a la toma de la palabra de un sector históricamente negado del derecho a la comunicación y del acceso al sistema mediático y, a su vez, se conformó como un espacio de reivindicación de las memorias y las culturas en un contexto de silenciamiento y discriminación.

La organización del discurso radial de La Voz Indígena, desde su creación como medio, priorizó como ejes temáticos las luchas territoriales (Doyle, 2018), las manifestaciones en defensa de la cultura y la identidad en contra del racismo y la discriminación, las luchas de género de las mujeres y personas de identidades no binarias de la zona (Ortega, 2020). En 2017, ARETEDE y la radio, emprendieron un proceso de fortalecimiento de las disputas por el territorio y contra la depredación de la naturaleza, a partir de los casos de las comunidades Territorios Originarios Wichi y Las Palmeras.

\section{Neoliberalismo: un concepto en movimiento}

Entendemos al neoliberalismo desde los aportes de Michel (Foucault, 2007), quien lo definió como una racionalidad de gobierno promotora 
de tecnologías específicas destinadas a extrapolar e incorporar el formato de economía de mercado al tejido social, instaurando "relaciones estrictamente mercantiles en la sociedad" (p. 155).

La propuesta foucaulteana introdujo una manera innovadora de entender el neoliberalismo, partiendo de la pregunta por los modos de gobierno desplegados por los sujetos a lo largo de la historia. Desde esa perspectiva, el neoliberalismo constituye una forma de conducción social, no universal y dinámica, características que complejizan las estrategias y expresiones que adquieren las tecnologías neoliberales en cada sociedad.

$\mathrm{El}$ análisis que realiza Foucault en cuanto al neoliberalismo en $\mathrm{Na}$ cimiento de la biopolítica remarca la constitución de un mecanismo particular centrado en la empresa como modelo social. En este sentido, Foucault (2007) señala:

¿Qué función tiene esa generalización de la forma "empresa"? Por un lado, se trata, desde luego, de multiplicar el modelo económico, el modelo de la oferta y la demanda, el modelo de la inversión, el costo y el beneficio, para hacer de él un modelo de las relaciones sociales, un modelo de la existencia misma, una forma de relación del individuo consigo mismo, con el tiempo, su entorno, el futuro, el grupo, la familia.... El retorno a la empresa es a la vez, entonces, una política económica o una política de economización de la totalidad del campo social, pero también una política que se presenta o se pretende como una vitalpolitik cuya función será compensar el frío, impasible, calculador, racional, mecánico juego de la competencia propiamente económica. (p. 278).

Nikolas Rose (1997) un pensador de orígenes británicos, estudioso del neoliberalismo desde la perspectiva foucaulteana, considera que entre el liberalismo y el liberalismo avanzado o neoliberalismo se han producido principalmente tres transformaciones que es necesario explicitar:

- nuevas relaciones entre los expertos y la política, lo que se evidencia en la extrapolación de regímenes de cálculo de auditoría financiera y de contabilidad a las formas de gobierno;

- pluralización de las tecnologías sociales, especialmente en la mutación del concepto de "lo social" a formas comunitarias de autogo- 
bierno, y la incorporación de "modos particulares de cálculo en los agentes y la suplantación de ciertas normas, como las de servicio y dedicación, por otras, tales como las de competitividad, calidad y demanda de los usuarios" (Rose, 1997, p. 36); y finalmente,

- la formación de un nuevo sujeto de gobierno, el cual procura su auto-realización individual, mediante el cálculo y la previsión de metas.

Un rasgo fundamental del neoliberalismo, partiendo de lo enunciado por Foucault, es su versatilidad y capacidad de dinamismo, razón por la cual, es necesario entender qué características adquiere en cada espacio de gobierno específico. En Argentina, el neoliberalismo, luego de una larga historia de gobiernos que oscilaron entre lógicas puramente neoliberales - como es el caso del menemismo y de gobiernos de corte popular mixto, como el kirchnerismo-, la llegada del macrismo significó un retorno a las concepciones neoliberales.

A pesar de que aún no se encuentran estudios completos referentes al neoliberalismo durante el gobierno macrista, tomamos los aportes de Sacchi quien, siguiendo la premisa foucalteana de la generalización del formato empresa, entiende el neoliberalismo como una ethopolítica que supone una pedagogía de la crueldad, expresada en la "precariedad laboral y sobre todo existencial, pobreza, desigualdad política y social, racialización y generización excluyente de los cuerpos y los modos de vida" (Sacchi, 2017, p. 61).

Por su parte, para Montes Cantó y Ventrici (2017) el gobierno de Mauricio Macri combinó un programa de enfoque "desregulatorio de la actividad financiera, la liberalización del flujo de capitales y la pérdida de herramientas de fiscalización en materia cambiaria" (p. 665) con acciones culturales y políticas tendientes a la polarización de la sociedad. El cercenamiento de la economía y el impacto directo en los sectores populares, sumado al clima social conflictivo, terminaron por conformar un escenario de gran división y crisis.

Estudios previos han abordado las problemáticas del norte de la provincia de Salta, donde algunos de los aportes más destacados son: los análisis acerca del gobierno de la pobreza y la implementación de políticas desarrollistas de corte neoliberal (Álvarez Leguizamón, 2015; Paulizzi y Milana, 2015); el proceso de incorporación de los pueblos 
indígenas a los mecanismos de gobierno estatal (planes y programas) y las instancias de ciudadanización (Flores Klaric, 2015); las políticas agrarias y las tensiones con los derechos ambientales (Naharro, Flores Klaric y Álvarez, 2015), entre otras.

Para Flores Klaric (2015) el acceso a la ciudadanía de los pueblos originarios del departamento San Martín a través de la creación de normativas, del reconocimiento de derechos y de la formalización de instituciones indígenas como el caso del Instituto Provincial del Aborigen (IPA) y del Instituto Provincial de Pueblos Indígenas de Salta (IPPIS), no repercutieron directamente en el mejoramiento de las condiciones de vida de la población originaria. La autora expresa:

los avances en materia legal y el paso a nivel de las políticas de Estado de un modelo monista a otro multicultural, fueron insertándose en un contexto social y económico crítico producto de la misma reforma de Estado hacia un modelo económico y político neoliberal. Esto en el ámbito local se tradujo en una serie de privatizaciones de lo público, y tuvo como consecuencia una crisis generalizada, asociada a la falta de trabajo que desencadenó movilizaciones y reclamos, por parte de los trabajadores desocupados a las que se sumaban las comunidades indígenas de sectores urbanos de Tartagal. En este proceso se amplía la brecha social entre los sectores pobres que pierden el acceso a derechos anteriormente garantizados por el Estado y, a la vez, emergen nuevos agentes del capital transnacional que van a redefinir el espacio a favor de las actividades extractivas y agrícolas con fuerte impacto en áreas de ocupación indígena, generándose múltiples conflictos. (Flores Klaric, 2015, p. 153).

\section{Neoliberalismo extractivista y reconfiguración de las estrategias de gobierno durante el período 2016-2019: territorios y cuerpos de mujeres}

La asunción de Mauricio Macri de la mano de la coalición CAMBIEMOS a la presidencia argentina, significó un marcado retroceso en materia de derechos humanos, lo cual se vio graficado en la proliferación de discursos de odio contra ciertos sectores de la población argentina, entre ellos, los pueblos originarios y el crecimiento de acciones punitivas contra las protestas sociales y líderes populares. Al respecto, Barros y Quintana (2020) analizaron las operaciones discursivas de la gestión 
CAMBIEMOS, señalando como característica principal la edificación de una clara frontera entre un "nosotros" idealizado y una otredad abyecta. Estas autoras observan también que los discursos de odio estaban dirigidos "hacia una multiplicidad de otros, de figuras amenazantes que, al ser caracterizadas como instigadoras de daños, también resultaban (auto) merecedoras de violencia" (Barros y Quintana, 2020, p. 88).

Para Barros y Quintana (2020) "el odio no se puede encontrar en una figura, sino que funciona para crear un contorno de diferentes figuras u objetos de odio, que son reunidas en una narración que las posiciona como una "amenaza común" (p. 89). De esta manera, diferentes sujetos - entre ellos, los pueblos originarios-, fueron enunciados como amenazas al orden establecido y al modelo de país propuesto.

Además del clima "antiderechos humanos", el gobierno macrista impulsó un conjunto de acciones destinadas a la desregulación del sector agrario argentino, dando rienda libre al crecimiento de los cultivos de soja y del campo en general. Medidas como el desmantelamiento de la Secretaría de Agricultura Familiar (SAF), la eliminación de impuestos a las exportaciones de granos como el trigo y el maíz y la reducción de las retenciones a la soja dan cuenta del posicionamiento político a favor de la expansión de la frontera agropecuaria.

En este contexto, las comunidades wichis Territorios Originarios y Las Palmeras comenzaron a recibir amenazas y presiones para desalojar sus territorios, y también a ser objeto de intromisiones de privados para talar ilegalmente el monte nativo. A lo largo de la ruta nacional 86 puede observarse el crecimiento del negocio forestal de extracción de madera y de los cultivos de soja, con grandes extensiones de tierra sembrada.

Las decisiones del gobierno incidieron directamente en la creación de un clima hostil para los pueblos indígenas, en el marco de un proyecto anclado en la exportación de granos, el mensaje nacional era claro: las grandes extensiones de tierra sirven a fines mercantiles. Contar con o reclamar grandes porciones de territorio y que no fueran para su uso productivo, era desalentador. Hechos de violencia, golpes, amenazas sucedían en la ruta 86 como formas de marcar el dominio y el triunfo del campo a la par del gobierno nacional.

Como podemos observar, cuando hablamos de las poblaciones indígenas del norte de Salta, nos referimos a problemáticas de larga data. 
No obstante, consideramos que con la asunción del gobierno de Mauricio Macri se inauguró un período de reorganización de las estrategias de gobierno de la pobreza, esta vez mediante el despliegue de acciones de descentralización del Estado y de transferencia de responsabilidades y fondos a fundaciones y ONG de corte caritativo, principalmente asociadas a sectores conservadores de la iglesia católica.

En alianza con el gobierno de la provincia de Salta, se creó el Ministerio de Primera Infancia y se cedieron fondos a fundaciones vinculadas con el médico Abel Albino, entre ellas la Cooperadora para la Nutrición Infantil (CONIN), Pata Pila y El Fortín, con el objetivo de combatir la pobreza y la desnutrición. En consonancia con las ideas del mencionado medico sanitarista, las deficiencias en la infancia temprana fueron identificadas como las causantes de la desnutrición, por lo tanto, la meta del programa era acompañar la crianza.

Las acciones de acompañamiento de la crianza se centraron en los cuerpos de las mujeres indígenas, con el propósito de modificar sus conductas mediante políticas alimentarias de control y seguimiento y de procedimientos invasivos, higienistas y culpabilizantes. El Ministerio de Primera Infancia jugó un rol importante en el posicionamiento del por entonces gobernador de Salta, Juan Manuel Urtubey, en contra del proyecto de Interrupción Voluntaria del Embarazo. Este organismo representaba su gestión a favor de la vida desde el nacimiento y, a su vez, era ejemplo del trabajo de prevención de embarazos adolescentes que implementaba la provincia con el Proyecto Horus (El Tribuno, 2019), el renombrado mecanismo de inteligencia artificial creado para identificar futuras madres adolescentes, el cual dependía del mencionado ministerio.

El traslado de la responsabilidad estatal a organismos autónomos consolidó una política de omisión y desatención de las demandas de las poblaciones indígenas, el cual se apoyó en la creación de una imagen de "bondad y solidaridad" de quienes llegaban a estos territorios a trabajar de manera desinteresada, pese a que recibían financiamientos estatales.

El testimonio de una de las directoras de ARETEDE y FM Comunitaria La Voz Indígena grafica y denuncia la situación de las mujeres indígenas: 
Como mujer indígena y directora de una organización de mujeres originarias, quiero expresar la gravedad de las violaciones a derechos que sufrimos las mujeres. Actualmente padecemos muchas problemáticas que nos afectan, principalmente la violencia de género que se expresa no solo físicamente, sino también en el maltrato en los hospitales, donde vivimos situaciones de discriminación sistemática por nuestra condición de mujeres indígenas; también padecemos violencia por parte de instituciones como la Justicia. Es muy difícil que una mujer originaria y rural pueda acceder a los mecanismos de acceso a la justicia. Al mismo tiempo, nos arrebatan niños y niñas con diferentes excusas, quienes son puestos en hogares estatales y en muchos casos dados en adopción. Padecemos también muchos casos de violaciones a niñas de nuestras comunidades.

Por todas estas situaciones, las mujeres estamos en pie de lucha y organizadas y exigimos al gobierno argentino, el respeto y cumplimiento de los derechos territoriales mediante la entrega de nuestras tierras y poder contar con servicios de salud dignos y que respeten nuestra cultura.

Exigimos que las mujeres seamos respetadas y que se cumplan nuestros derechos para que no seamos discriminadas, marginadas y violentadas. (Testimonio extraído de FM Comunitaria La Voz Indígena, 2019)

A modo de resumen, consideramos que con las políticas y medidas tomadas por el gobierno macrista se consolidó una estrategia de gobierno basada en el control de territorios y cuerpos de mujeres. Los primeros, apropiados para su aprovechamiento productivo, en consonancia con sus planes de desarrollo extractivista; y los segundos, dispuestos a la civilización, mediante la asimilación de nuevas prácticas para la crianza de los niños. La dominación de las mujeres indígenas aseguraba directamente la solución de la desnutrición, puesto que sus cuerpos y conductas eran concebidos como el núcleo problemático.

En este contexto, el crecimiento de la pobreza y el agravamiento de las condiciones territoriales precarias, terminó por conducir a una grave crisis socioambiental. Las formas de creación colectiva de los pueblos originarios se enfrentaron a nuevas condiciones y debieron rearmar sus procedimientos a fin de sobrevivir. 


\section{Resistencias contemporáneas y comunicación: ARETEDE y FM Comunitaria La Voz Indígena}

Aunque poco se conoce de los procesos de resistencia a la conquista de los pueblos indígenas chaquenses, estas poblaciones lideraron grandes rebeliones contra las campañas militares desde mediados del siglo XIX. Los aportes de Kantor (2012) en cuanto a la resistencia del pueblo Toba Qom del Pilcomayo, al igual que los diarios de viaje de Thuar (1997) y las expediciones de los franciscanos y otros viajeros en los ríos Bermejo y Pilcomayo (Santamaria, 2008; Teruel, 1995; 2005) son abordajes etnográficos y testimonios que dan cuenta de las batallas entre indígenas y militares.

En la contemporaneidad, a pesar de la fuerte crisis posconquista, los pueblos indígenas del norte de Salta motorizaron formas de resistencia en escalas diversas, que incluyen manifestaciones públicas, cortes de ruta, marchas, presentaciones judiciales y alianzas con instituciones para poder realizar denuncias y recibir acompañamiento jurídico, entre otras. Puntualmente, este trabajo reflexiona acerca del lugar de la comunicación en las resistencias contemporáneas de ARETEDE y FM Radio Comunitaria La Voz Indígena.

Lo que podemos denominar bajo el título de "resistencias contemporáneas" alude a los procesos organizativos que desarrollan los pueblos originarios del norte de Salta, contra el avance sobre sus territorios y el avasallamiento sobre sus culturas y formas de vida.

ARETEDE y FM Radio Comunitaria La Voz Indígena constituyen una organización que nuclea a un conjunto de personas de los pueblos Wichi, Guaraní, Toba Qom y Chorote. El nacimiento de esta organización, a fines de 1990, se inscribe en el proceso de reemergencia de los movimientos indígenas luego del retorno a la democracia en 1983 (Trinchero y Valverde, 2014), momento en el que tuvo lugar una etapa de paulatino reconocimiento de derechos, cuyo punto más álgido fue la incorporación del artículo 75 inciso $17^{2}$ en la reforma de la Constitución Argentina en 1994.

2 Este artículo reconoce que los pueblos indígenas son preexistentes a la formación del Estado argentino. 
A lo largo de su existencia, este colectivo se dedicó, por un lado, al trabajo con mujeres e identidades no binarias, realizando diferentes acciones de capacitación, apoyo a proyectos comunitarios, procesos organizativos de lucha contra la violencia de género, y la realización de productos comunicacionales y culturales en torno a la memoria étnica de los pueblos originarios de la zona, trabajos plasmados en la publicación de los libros Lunas, Tigres y Eclipses: La Voz de las Mujeres Indígenas (ARETEDE, 2003) y El anuncio de los pájaros: voces de la resistencia indígena (ARETEDE, 2005). Por otro lado, el colectivo se enfocó en el proceso de acompañamiento territorial a comunidades desalojadas o en procesos de litigio judicial, como son los casos de Yariguarenda, Quebracho, Territorios Originarios Wichi y Las Palmeras.

Producto del largo proceso de organización y capacitación, ARETEDE logró inaugurar en 2008 su propia emisora radial, llamada FM Radio Comunitaria La Voz Indígena, el primer medio de pueblos originarios de la zona. En la actualidad, la organización es un colectivo diverso, que reúne a comunicadores, artistas y artesanas mujeres, personas de identidades no binarias, y varones de pueblos indígenas. ARETEDE es conducido por un equipo directivo conformado por tres mujeres fundadoras, quienes pertenecen a los pueblos Toba Qom, Wichi y Guaraní.

Desde 2015, ARETEDE lleva adelante un proceso de lucha colectiva, centrado en varias comunidades, pero especialmente en las siguientes: Territorios Originarios Wichi y Las Palmeras, ambas del pueblo Wichi. Nos interesa indagar en las estrategias de resistencia desplegadas y en la forma en que confluyen las luchas territoriales, ambientales y de género en territorios marcados por el extractivismo y la pobreza.

A lo largo de la ruta nacional 86 se concentra la mayor cantidad de poblaciones Wichi de Tartagal, denominadas "comunidades". En este conglomerado periurbano no solo conviven pueblos originarios, sino que se desarrollan actividades agrícolas a gran escala, especialmente de soja, maíz y poroto, como así también actividades forestales de extracción de madera. La ocupación territorial de los territorios por parte de titulares registrales privados dio como resultado la comercialización de los suelos y la expulsión de los indígenas de sus espacios ancestrales. 
Los años de expoliación y despojo han empeorado las condiciones de vida de las poblaciones indígenas, las que en la actualidad se ven afectadas directamente por las fumigaciones con agrotóxicos y la consecuente proliferación de enfermedades terminales. Las problemáticas ambientales se evidencian en la tala intensiva de los montes nativos, la pérdida de biodiversidad y sus efectos nocivos sobre la salud y la cultura de los pueblos originarios, quienes se enfrentan cotidianamente a problemas derivados de la compleja situación.

ARETEDE, como ya mencionamos, es una organización liderada por un conjunto de mujeres indígenas, cuyas acciones presentan como lema la igualdad de género y la existencia de una conducción en clave de feminismo interseccional. En la agenda de ARETEDE confluyen temáticas propias de las luchas de género, directamente vinculadas con la pertenencia étnica y de clase, pero a su vez, dan cuenta del liderazgo de las mujeres en las luchas territoriales, haciendo de sus voces y planteos, la guía de las estrategias y acciones de disputa.

Desde la interseccionalidad (Crenshaw, 2011; Platero, 2012), entendida como la interacción entre factores raciales, de género, étnicos y de clase en las vivencias de las mujeres, este grupo pudo dar forma a un colectivo cuya posición política asume la lucha de pueblos que provienen de historias de horror y matanzas, invisibilizadas, sobre las cuales se construye cotidianamente una sociedad extractivista y colonial.

Mediante marchas, encuentros, talleres y presentación de proyectos a diferentes organismos estatales y no gubernamentales, ARETEDE logró instalar en la agenda pública de la sociedad tartagalense, las proclamas de las mujeres indígenas. "Aquí estamos, queremos ser escuchadas" y "Justicia, tierra y libertad" fueron los ejes discursivos de las marchas realizadas en el marco de los Encuentros Departamentales de Mujeres Indígenas, eventos que tuvieron lugar desde 2001 hasta 2006.

Los primeros discursos de la organización se conformaron a partir del trabajo de recuperación de narrativas en torno a la memoria étnica de los pueblos que habitan la zona, así es que surgieron las primeras proclamas de resistencia. Castelonuovo (2017) señala que en los Talleres de Memoria Étnica dictados por ARETEDE, se hizo presente una 
reconstrucción histórica que permitió "que las mujeres inscribieran sus luchas del presente en una genealogía de luchas pretéritas por la tierra" (p. 114).

Siguiendo a Jelin (2002), en este caso la memoria actuó como un "mecanismo cultural para fortalecer el sentido de pertenencia" (p. 9), acentuar la referencia a un pasado común y reorganizar las resistencias en el presente. Temas como las guerras de los pueblos Toba Qom y Guaraní contra los militares, las batallas lideradas por el cacique Taikolic (Combes, 2019) y los relatos de masacres y emboscadas, fueron el eje discursivo que luego se trasladó a la radio comunitaria.

Así, la radio desempeña un rol clave en la visibilización de los reclamos de los pueblos, principalmente en tres aspectos: la irrupción de las voces indígenas en la agenda mediática local, la disputa simbólica por el desmantelamiento del estigma racista creado en torno a los pueblos indígenas, en especial de las mujeres y la construcción de una nueva subjetividad indígena.

Las voces de la resistencia es el slogan de la FM Comunitaria La Voz Indígena. Este medio es el espacio de difusión y organización de ARETEDE, cuyo rol es central en la incidencia y proyección de las luchas de los pueblos originarios. A través de la radio, los referentes indígenas pueden denunciar y dar a conocer públicamente diferentes problemáticas.

A principios de 2017, producto del crecimiento de la frontera agropecuaria, en consonancia con los discursos y políticas implementadas por el gobierno que buscaban convertir a la Argentina en el "granero del mundo", las comunidades wichis de la ruta nacional 86 fueron objeto del recrudecimiento de amenazas y presiones para abandonar sus territorios.

A través del aumento de la tala ilegal, del tráfico de madera, del crecimiento de los sembrados de soja y de actos intimidatorios a los referentes de las colectividades, las empresas y terratenientes intensificaron un proceso de expulsión y coacción sobre las comunidades indígenas. En este clima hostil, un conjunto de comunidades nucleadas en torno a ARETEDE inició un proceso de resistencia anclado en la comunicación y el reclamo de justicia, con el objetivo de proteger el monte nativo. 


\section{Luchas y resistencias: comunicación, derechos y cuerpos}

Las comunidades Territorios Originarios Wichi y Las Palmeras, ubicadas en los márgenes de la ruta nacional 86 junto con la organización ARETEDE y FM Radio Comunitaria La Voz Indígena decidieron activar estrategias de defensa y protección de sus territorios, de la naturaleza y de sus vidas. Nos preguntamos puntualmente ¿a través de qué acciones?, ¿qué nociones se desplegaron?, ¿cómo incidieron en la opinión pública?

Con el objetivo de frenar el avance de destrucción del monte nativo y de continuar reclamando la propiedad comunitaria de sus territorios, este conjunto de actores, dispuso una serie de medidas colectivas. Principalmente, identificamos la presencia de dos instancias: la comunicación y el derecho.

La radio, tal como afirma María Cristina Mata (1993) constituye un hecho social y una práctica significante. Siguiendo esta perspectiva, en este caso, la radio comunitaria fue el espacio que permitió colectivizar intereses, opiniones y planteos para el establecimiento de una agenda común de lucha y resistencia. Desde la radio, se elaboraron mensajes y el tema ocupó lugares importantes en la programación de la emisora, transformándose en el principal medio de Tartagal en dar cobertura a las marchas y movilizaciones.

El lugar que ocupa la radio comunitaria en las luchas de los pueblos originarios del norte de Salta trasciende las concepciones instrumentales que reducen la importancia de los medios a una función tecnológica, por el contrario, la comunicación radial es la práctica que les permite socializar sus voces e instalar en la agenda mediática y pública temáticas silenciadas e invisibles en los demás medios de comunicación locales.

La denuncia pública a través de la radio fue la principal estrategia de lucha del colectivo, por ejemplo, en instancias de una orden de desalojo dictada para la comunidad Las Palmeras, ARETEDE organizó un video que fue subido a las redes sociales de la radio, en el que se denunció el hecho. "Nuestra lucha es en defensa del territorio. Basta de injusticia" ${ }^{3}$ rezaba el cartel de Rafael Segundo, cacique de la comunidad.

3 El video se encuentra disponible en el siguiente enlace: https://www.facebook. com/watch/?v=344653932920556 


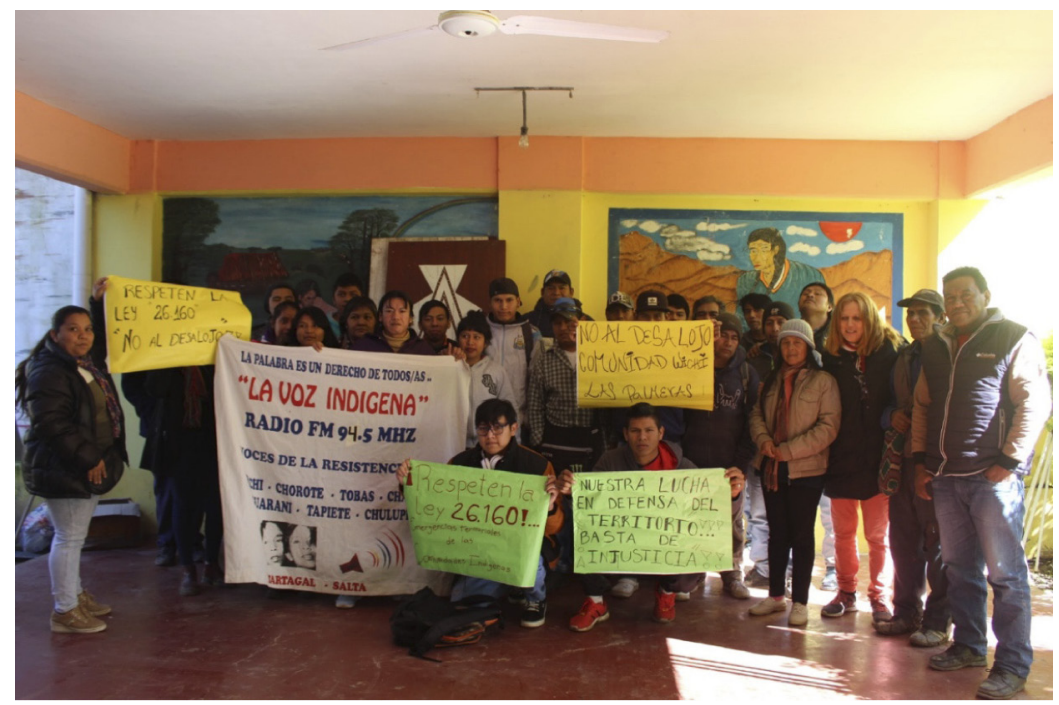

Figura 1. Organización del video para denunciar la orden de desalojo a la comunidad Las Palmeras.

Fuente: Elaboración propia.

La cobertura de los hechos - atendiendo a toda la complejidad de la relación entre la cultura, la identidad y la historia de los pueblos indígenas-, constituye una característica de la radio. Puntualmente, en el caso de la comunidad Las Palmeras, la construcción de la noticia destaca el modo en que la radio es apropiada por parte de los pueblos originarios. Cuando llega la notificación de desalojo, las autoridades se dirigen directamente a la radio pidiendo salir al aire.

La construcción de la noticia del caso de Las Palmeras retoma la historia de la comunidad, la amenaza de desalojo y las condiciones en que se produjo. El cacique, al dar su testimonio, expresa que no sabe leer ni escribir y que fue engañado para firmar. ${ }^{4}$. A partir de este hecho, la organización instala el tema en su programación, le da continuidad y pone en marcha movilizaciones y estrategias para dar visibilidad al caso. Por ejemplo, el siguiente fragmento es parte de la entrevista realizada a los involucrados en el hecho:

4 Video disponible en el siguiente enlace: https://www.facebook.com/watch/live/?v $=2305681839525319 \&$ ref=watch_permalink 
Nos hicieron firmar la orden de desalojo sin explicación, sin explicarnos por qué, nos hicieron firmar con engaños, sin conocer a fondo. Pedimos a las autoridades que lo frenen porque esa parte tiene reconocimiento territorial remarcado, pedimos a las autoridades que lo frenen y acompañen todo, lo antes posible (sic). (Testimonio extraído de los videos difundidos por FM Comunitaria La Voz Indígena).

Cerbino y Belloti (2016) afirman que los medios comunitarios se diferencian de otros en la forma en que construyen sus agendas, tumbando los criterios de noticiabilidad tradicionales y priorizando las temáticas locales. En este caso, la forma de construcción de las noticias y la agenda temática de la radio están conectadas directamente con las demandas de los pueblos originarios de la zona.

Análogamente una situación tuvo lugar en el caso de la comunidad Territorios Originarios Wichi, amenazada por la tala del monte nativo de su territorio. Desde 2017 a través de la radio se denunciaron los numerosos hechos de desmonte y atropellos contra la naturaleza. El cacique de la comunidad manifestó en reiteradas oportunidades la importancia del monte nativo para su pueblo, ya que cada árbol talado es una herida. Nuevamente la comunicación fue la principal estrategia de activismo de los pueblos originarios, consiguiendo instalar el tema en la agenda mediática y política. A continuación, el testimonio de uno de los líderes de la comunidad:

Soy XXX, cacique de la comunidad Territorios Originarios Wichi, denuncio hoy a los otros hermanos, que se adueñan de desmontar y atropellar a las comunidades, sin consulta, sin saber cómo viven las personas, entonces no hay necesidad de no respetar. Yo creo que sí tengo derecho de hacer una denuncia contra estas malas actitudes de los gobiernos, el gobierno quizás no sabe, pero nosotros hemos hecho muchos esfuerzos para solucionar el problema y tramitar que haya personerías jurídicas en el territorio originario, entonces tanto atropellos de las vacas y de los desmontes, ya la comunidad se harta de verlos cómo destrozan y cómo desesperan (sic). (Testimonio extraído de los videos difundidos por FM Comunitaria La Voz Indígena).

La perspectiva de derechos humanos atraviesa transversalmente la experiencia. En efecto, desde su emergencia a fines de los 90 has- 
ta la actualidad, los activistas y comunicadores se formaron como defensores de derechos humanos, hecho que se refleja en los casos en estudio, los cuales impulsaron acciones judiciales de protección de sus derechos, acompañados por abogadas activistas y por un equipo de profesionales de las ciencias sociales que colabora con el colectivo.

El derecho se constituyó en el principio argumentativo del discurso radial y también en fuente de protección y resguardo ante los atropellos sufridos. La relación entre la comunicación y el derecho nos conduce a pensar en la noción de ciudadanía comunicacional desarrollada por Mata $(2006 ; 2011)$ quien la define como:

el reconocimiento de la capacidad de ser sujeto de derecho y demanda en el terreno de la comunicación pública, y el ejercicio de ese derecho ... la ciudadanía comunicativa representa un límite a la acción del Estado con el fin de garantizar la libertad de las personas y representa un estatus jurídico. (Mata, 2006, p. 13).

El derecho a la comunicación actuó como posibilitador de la demanda de cumplimiento de los demás derechos indígenas, en especial, los referidos a los reclamos territoriales. La articulación entre comunicación y derecho posibilitó la configuración de un complejo sentido de resistencia y lucha, cuyos rasgos se exhiben en la presencia de componentes de demandas étnicas de autonomía, ambientales y de género dirigidas hacia interlocutores diversos, el Estado, la sociedad próxima, empresarios, etc.

La resistencia constituye una práctica política cotidiana y un ensamblaje construido en torno a la experiencia colectiva, retomando los aportes de Foucault (1995) para pensar la crítica como las formas de no ser gobernado, entendemos que, en este caso, el ejercicio de la resistencia al neoliberalismo se practica mediante un conjunto de acciones colectivas que reniegan del gobierno y que inventan formas de esquivar los numerosos intentos de control y sometimiento.

Ante el advenimiento de una sociedad promotora de odio racial hacia los pueblos indígenas y sus reivindicaciones y del avance de tecnologías neoliberales sobre sus territorios y cuerpos, el colectivo de ARETEDE opuso la denuncia y la exhibición de sus rasgos y dolores en la escena pública como estrategias de sensibilización e impacto. 
Cuerpos y voces de mujeres, transgéneros y varones indígenas visibles en la escena pública, arrojados voluntariamente para dar cuenta de su existencia y desafiar al Estado "blanco", formaron acontecimientos en los que el cuerpo constituyó el mismo campo de resistencia y lucha. Sus rasgos, mensajes, palabras y gestos irrumpieron ante la sociedad de Tartagal para marcar una presencia y dejar mensajes contra el racismo, la injusticia y la depredación de la naturaleza.

Desde la palabra y la corporalidad este colectivo se enfrentó a la profundización del extractivismo y a un inusual contexto de promoción de la comercialización y explotación de la tierra. Poniendo al aire anuncios de árboles y pájaros y portando estandartes de protesta con mensajes que hablan de la tierra, reinventaron la resistencia indígena en clave contemporánea. Un mensaje que salió al aire por la radio es el siguiente:

Vemos este tronco de árbol seco y podría ser que nosotros lo hemos dañado, estas lágrimas son el símbolo de que está brotando y veremos cómo va a ir creciendo, tal como lo hacemos nosotros con nuestra existencia. Este sería su espíritu, lo que emana de este tronco viejo, que bien podría ser pasto, lianas, o cualquier otra especie, de la misma manera en que dejamos esta tierra, al terminar nuestro día, y ya no existamos más. Volvemos a la tierra, pero nuestros espíritus permanecerán entre todos los demás seres, y no se sufre de esta condición porque es algo natural y es aceptable. (spot radial emitido por FM Comunitaria La Voz Indígena, 2019).

La colectivización de experiencias y causas compartidas frente a las técnicas individualizantes del neoliberalismo conformaron una apuesta con aristas que exceden este artículo, pero que son importantes de mencionar, esto es, la formación de un corpus discursivo disidente que denuncia la violación de derechos de las mujeres indígenas, puntualmente el despliegue de acciones culpabilizantes y civilizatorias, las diferentes formas de violencia de género y la desigualdad en el sistema educativo; la pugna por la participación e inclusión de las causas indígenas en las agendas de gobierno locales son algunos de los reclamos más importantes.

Esta comunidad, al igual que Las Palmeras, se enfrenta además a las acciones extractivistas y litigios por la propiedad de los territorios, 
puesto que son extensiones de tierra con titularidad privada. El reclamo evidencia la existencia de dos formas contrapuestas de entender al territorio, y cuestiona la manera en que el Estado prioriza el derecho a la propiedad privada y omite el cumplimiento de los derechos indígenas.

El acceso comunitario a los territorios, el respeto a sus pautas culturales, a sus identidades son derechos asumidos por el Estado argentino, al igual que los derechos ambientales y de protección de los bosques, por ejemplo, mediante la Ley 7.543 de Ordenamiento Territorial de los Bosques Nativos. Sin embargo, la voluntad política para su efectivo cumplimiento por lo general oscila entre el desinterés y la omisión.

El crecimiento de las actividades extractivas tiene como base común la concepción mercantilista con la cual se entiende al territorio, los criterios de relación y medición del uso de la tierra y las actividades por realizar en él, los que aún son utilitarios y reducen la tierra a un recurso económico. En ese marco, el planteo de la organización de mujeres indígenas ARETEDE en conjunto con las mencionadas comunidades, es un llamado y una propuesta a la sociedad en general, que habla de la movilización y la vida en pueblos y territorios marginales.

¿Cómo se defiende la vida en estos territorios?, ¿pueden hablar y defenderse esos pueblos pensados e imaginados como incapaces? La experiencia de ARETEDE, Territorios Originarios Wichi, Las Palmeras y La Voz Indígena hace visible cómo es posible luchar por la vida humana y no humana. En condiciones de sometimiento cultural y de pobreza, estas voces y cuerpos cuestionaron los modelos de desarrollo basados en la depredación de la naturaleza y reclamaron su derecho a estar libremente con la naturaleza y los seres que la habitan sin ser presionados para entregarse a la productividad.

Entendemos que en este caso la resistencia es poliforme y multidimensional, con características complejas, que relacionan el acto de resistir con la memoria colectiva de los pueblos, sus efectos en el presente y la transformación de las luchas. El rol de las mujeres en la redefinición de la agenda política y en el horizonte colectivo complejiza las experiencias contemporáneas. Denunciando el machismo, las violencias de género y construyendo una resistencia organizada para lograr un presente y futuro justo, las mujeres abrazaron las causas de comunidades y personas que reclaman ante el avance de sobre sus vidas. 
Los activismos de los pueblos originarios congregados en ARETEDE disputan el sentido del "ser indígena" en el presente, con reclamos que aúnan demandas de derechos y que pugnan por condiciones que exceden los entendimientos occidentales. Reclamos de género, de libertad y justicia para las mujeres e identidades no binarias, se fusionan con causas históricas: la devolución de sus territorios y el cumplimiento de derechos que les permitan vivir mejor.

\section{Conclusiones}

El fenómeno neoliberal en América Latina permanece como un programa generador de conflictos y problemáticas diversas. El caso de los pueblos originarios es probablemente uno de los más emblemáticos, ya que el control de los territorios para la implementación de operaciones extractivistas es el sostén primario de las estrategias de lo que Harvey (2005) denomina acumulación por desposesión. La mercantilización de la naturaleza impacta directamente en la propiedad de los territorios originarios, como en las discusiones de fondo del caso en estudio.

La resistencia a las maniobras de apropiación territorial y, en consecuencia, de los elementos que componen los territorios (no solo la tierra en sí misma, sino los árboles y los seres de la naturaleza, como espíritus y animales, fundamentales para las culturas indígenas) se inscribe en un marco de crisis en el cual las posibilidades de los pueblos indígenas se ven limitadas por la carencia de medios económicos para sostener litigios y estrategias judiciales.

El avance de los desmontes y las plantaciones de soja y otros cultivos, afectan a poblaciones indígenas de la zona en dos aspectos fundamentales: por un lado, en el desplazamiento poblacional y la fragmentación de los grupos que forman las comunidades, y por otro, en el daño ecológico que afecta a la sociedad en su conjunto. A partir de estos efectos, se agudizan la carencia de medios y recursos para la alimentación, la salud, el acceso al agua, etc.

A la par de la depredación de la naturaleza, las acciones de patologización de las mujeres, puestas en el centro de las intervenciones estatales para modificar sus roles como madres y responsables de la crianza, no hacen otra cosa que exponer las formas en que se multi- 
plican y renuevan las redes civilizatorias y patriarcales de violencia y dominación.

El sistema de intervención diseñado para el acompañamiento de la crianza constituye un entramado perverso que exhibe las racionalidades racistas que subyacen a las estrategias de gobierno, basadas en una lógica monocultural y occidental, donde las mujeres indígenas son el epicentro de las problemáticas, ignorando las responsabilidades paternales compartidas y atentando contra sus libertades.

En ese contexto, la comunicación se convierte en la forma primaria para vehiculizar y hacer públicas las demandas y denuncias, visibilizando los efectos negativos de los desmontes, los emprendimientos extractivistas y las políticas estatales. El caso de La Voz Indígena $y$, especialmente de las comunidades que analizamos, da cuenta de la importancia de la comunicación, pero no en forma aislada o como un acto espontáneo. Más bien, lo que observamos es un sentido organizado de acciones y estrategias, en el marco de un posicionamiento colectivo relacionado con el proyecto político cultural de la radio comunitaria: ser un medio de lucha.

La comunicación comunitaria se constituye como práctica de resistencia, un modo de llevar adelante las acciones para hacer visibles las problemáticas y constituirse como sujetos de acción frente a los adversarios (empresarios, autoridades que no cumplen sus funciones, etc.). Este modo trasciende la radio, las marchas, carteles e intervenciones en lugares públicos, pues introduce una dimensión que ensambla diferentes elementos comunicacionales y conforma un tejido estratégico y coherente con el rumbo de la organización.

Como hemos visto, en FM Comunitaria La Voz Indígena se intersectan varios factores, las dimensiones étnicas, de género y de clase, haciendo de esta experiencia un colectivo multifacético, que termina por sintetizar un complejo caso de dinamismo.

Nos interesa destacar que en el norte de Salta, las luchas territoriales son activas y que la creciente convulsión devenida de la expansión de los proyectos agroexportadores y el impacto sobre la naturaleza y los territorios, agravada durante la gestión macrista, se encuentra en la actualidad ante grandes interrogantes que plantean qué pasará con la postura de los organismos estatales, la justicia y las diferentes planifi- 
caciones de gobierno, nacionales, provinciales y municipales frente a la creciente depredación del monte.

\section{Referencias}

Agurto, J. y Mescco, J. (2012). La comunicación indígena como dinamizadora de la comunicación para el cambio social. Trabajo presentado en XI Congreso Latinoamericano de Investigadores en Comunicación. Montevideo, Uruguay. Recuperado de http://www.servindi.org/pdf/ALAIC_comunicaciónindigena2012.pdf

Álvarez Leguizamón, S. (Comp.). (2015). Neocolonialismo, capitalismo, pobreza y resistencias subalternas. Rosario: Prohistoria Ediciones.

Arcila Calderón, C., Barranquero, A., y González Tanco, E. (2018). From media to buen vivir: Latin American approaches to indigenous communication. Communication Theory, 28(2), 180201. https://doi.org/10.1093/ct/qty004

Asociación Regional de Trabajadores en Desarrollo, ARETEDE. (2003). Lunas, tigres y eclipses. La voz de las mujeres indígenas. Salta: Organización de los Pueblos Indígenas en Argentina.

Asociación Regional de Trabajadores en Desarrollo, ARETEDE. (2005). El anuncio de los pájaros. Voces de la resistencia indígena. Salta: Organización de los Pueblos Indígenas en Argentina.

Avellaneda, A. (2015). Las escalas del poder político. Artes, redes y técnicas en los estudios de gubermentalidad. Astrolabio, 14, 93120. Recuperado de https://revistas.unc.edu.ar/index.php/ astrolabio/article/view/10740

Baraldini, V., Cañicul, M., Cian, C., Chico, J., López, J. J., y Melillán, M. (2009). Comunicación con Identidad. Aportes para la Construcción del modelo de comunicación Indígena en Argentina. Buenos Aires: Instituto Nacional de Asuntos Indígenas, INAI.

Barranquero, A. y Sáez, C. (2015). Comunicación y buen vivir. La crítica descolonial y ecológica a la comunicación para el desarrollo y el cambio social. Palabra clave. Revista de Comunicación, 18(1), 41-82. https://doi.org/10.5294/pacla.2015.18.1.3

Barros, M. y Quintana, M. (2020). Elogios del amor y la violencia. Una aproximación a la retórica afectiva de Cambiemos. Pilquen Revista, 23(1), 80-92. Recuperado de http://revele. 
uncoma.edu.ar/htdoc/revele/index.php/Sociales/article/ view/2612/59393

Benclowicz, J. D. (2009a). Genealogía del movimiento piquetero de Tartagal-Mosconi, Salta, Argentina. 1920-2001 (Tesis de doctorado). Universidad de Buenos Aires, Buenos Aires, Argentina.

Benclowicz, J. D. (Septiembre de 2009b). La invención del Otro en el Chaco Salteño. De la Expropiación y el Trabajo Forzado de los Pueblos Originarios a la Segregación y la Invisibilidad. Trabajo presentado en VIII Jornadas de Sociología de la Universidad de Buenos Aires. Asociación Latinoamericana de Sociología, Buenos Aires, Argentina.

Buliubasich, C. y González, A. (2009). Los pueblos indigenas de la Provincia de Salta. La posesión y el dominio de sus tierras. Departamento San Martín. Salta: Centro Promocional de las Investigaciones en Historia y Antropología (CEPIHA)-Universidad Nacional de Salta.

Castelnuovo, N. (2017). Memorias territoriales en las luchas de los pueblos indígenas. Clepsidra. Revista Interdisciplinaria de Estudios sobre Memoria, 4(8), 108-131. Recuperado de http:// ppct.caicyt.gov.ar/index.php/clepsidra/article/download/ INTRODUCCI\%C3\%93N/pdf

Cerbino, M. y Belloti, F. (2016). Medios comunitarios como ejercicio de ciudadanía comunicativa: experiencias desde Argentina y Ecuador. Comunicar, Revista Científica de Educomunicación, 24(47), 49-56. https://doi.org/10.3916/c47-2016-05

Ceriani Cernadas, C. (2015). Campanas del Evangelio. La dinámica religiosa indígena en los ingenios azucareros del noroeste argentino. En L. Córdoba, F. Bossert, y N. Richard (Eds.), Capitalismo en las selvas: enclaves industriales en el Chaco y Amazonía Indígenas (1850-1950) (pp. 45-64). San Pedro de Atacama: Ediciones del Desierto.

Combes, I. (2019). Taicoliqui: fragmentos de una vida. Boletín Americanista lxix, 2(79), 9-27.

Crenshaw, K. (2012). Cartografiando los márgenes. Interseccionalidad, políticas identitarias, y violencia contra las mujeres de color. En L. Platero (Ed.), Intersecciones: cuerpos y sexualidades en la encrucijada (pp. 87-122). Madrid: Belaterra Ediciones.

Das, V. y Poole, D. (2008). El estado y sus márgenes. Etnografías comparadas. Cuadernos de Antropología Social, 27, 19-52. Recupe- 
rado de https://www.redalyc.org/pdf/1809/180913917002. pdf

Doyle, M. (2013). Los medios masivos de comunicación en las luchas de los pueblos indígenas. Abordajes desde los estudios sobre comunicación en América Latina (Tesis de maestría). Universidad Nacional de Córdoba, Córdoba, Argentina.

Doyle, M. (2018). Las luchas por territorios ancestrales en los medios indígenas. El caso de FM La Voz Indígena. Comunicación y Medios, 38, 177-189. https://comunicacionymedios.uchile. $\mathrm{cl} /$ index.php/RCM/article/view/50650

El Tribuno (2019). Primera Infancia es el ministerio que defiende a los niños desde su concepción. Recuperado de https://www.eltribuno.com/salta/nota/2019-3-27-0-39-0--primera-infancia-es-el-ministerio-que-defiende-a-los-ninos-desde-suconcepcion

Flores Klaric, M. (2015). El ingreso a la ciudadanía de los pueblos indígenas del área de Tartagal. Políticas públicas, instituciones indigenistas y la emergencia de organizaciones etnopolíticas (1945-2010). En S. Álvarez Leguizamón (Comp.), Neocolonialismo, capitalismo, pobreza y resistencias subalternas (pp. 105-154). Rosario: Prohistoria Argentina.

Foucault, M. (1982). Mesa Redonda del 20 de mayo de 1978. En M. Foucault (Ed.), La imposible prisión: debate con Michel Foucault (pp. 55-79). Barcelona: Anagrama.

Foucault, M. (1988). El sujeto y el poder. Revista Mexicana de Sociología, 50(3), 3-20. https://doi.org/10.2307/3540551

Foucault, M. (1995) ¿Qué es la crítica? Revista de Filosofía, 11, 5-25. https://revistas.um.es/daimon/article/view/7261

Foucault, M. (2000). Defender la sociedad. Curso en el Collège de France (1975-1976). Buenos Aires: Fondo de Cultura Económica.

Foucault, M. (2007). Nacimiento de la Biopolítica. Curso en el Collège de France (1978-1979). Buenos Aires: Fondo de Cultura Económica.

Grondona, A. (2009). La articulación de la pastoral católica y la gubermentalidad neoliberal en la gestión de las poblaciones liminares. En I. Cassigoli y M. Sobarzo (Eds.), Biopolíticas del Sur (pp. 387-398). Santiago de Chile: Editorial Arcis. 
Grondona, A. (2019). ¿Lost in translation? Una mirada periférica sobre los Governamentality Studies. En A. Avellaneda y G. Vega (Comps.), Conductas que importan. Variantes de análisis de los estudios en gubernamentalidad (pp. 13-45). Corrientes: Editorial de la Universidad Nacional del Nordeste, EUDENE.

Gumucio Dagrón, A. y Tufte, T. (2008). Antología de comunicación para el cambio social. Lecturas históricas y contemporáneas. La Paz: Plural Editores.

Harvey, D. (2005). El nuevo imperialismo. Acumulación por desposesión. Buenos Aires: Consejo Latinoamericano de Ciencias Sociales, CLACSO.

Herrera Huérfano, E., Sierra Caballero, F., y Del Valle Rojas, C. (2016). Hacia una epistemología del sur. Decolonialidad del saberpoder informativo y nueva comunicología latinoamericana. Una lectura crítica de la mediación desde las culturas indígenas. Chasqui. Revista Latinoamericana de Comunicación, 131, 77-105. Recuperado de https://revistachasqui.org/index.php/chasqui/article/view/2694/2738

Herrera Miller, K. (2006). ¿Del grito pionero... al silencio? Las radios sindicales mineras en la Bolivia de hoy. La Paz: Plural Editores.

Inda, X. (2005). Analíticas de la modernidad. Una introducción. En X. Inda (Ed.), Antropologías de la modernidad. Foucault, gubernamentalidad y políticas de la vida (pp. 1-20). Londres: Blackwell Publishing.

Iñigo Carreras, N. (1984). Campañas militares y clase obrera. Chaco, 1870-1930. Buenos Aires: Centro Editor de América Latina.

Iñigo Carreras, N. (2010). Génesis, formación y crisis del capitalismo en el Chaco 1870-1970. Salta: Editorial de la Universidad Nacional de Salta.

Jelin, E. (2002). Los trabajos de la memoria. Madrid: Siglo XXI.

Kantor, L. (2012). Rebeliones olvidadas y resistencias actuales entre los tobas del Chaco. (Tesis de grado). Universidad de Buenos Aires, Buenos Aires, Argentina.

Korol, C. (2006). Guerras y emancipaciones en las tierras del petróleo. En C. Korol (Comp.), Cortando las rutas del petróleo (pp. 5183). Buenos Aires: Asociación Madres de Plaza de Mayo.

La Nación (2016). Esteban Bullrich: “Esta es la nueva Campaña del Desierto, pero no con la espada sino con la educación". Recu- 
perado de https://www.lanacion.com.ar/politica/estebanbullrich-esta-es-la-nueva-campana-del-desierto-pero-nocon-la-espada-sino-con-la-educacion-nid1938454

Lizondo, N. (2018). La comunicación con identidad. Regulaciones y un estudio de caso. Anuario Electrónico de Estudios en Comunicación Social Disertaciones, 11(2), 1-18. https://doi. org/10.12804/revistas.urosario.edu.co/disertaciones/a.5745

Los Andes (2018). Macri dijo que "todos somos descendientes de europeos" y le llovieron las críticas. Recuperado de https:// www.losandes.com.ar/macri-dijo-que-todos-somos-descendientes-de-europeos-y-le-llovieron-las-criticas/

Marradi, A., Archenti, N., y Plovani, J. (2007). Metodología de las ciencias sociales. Buenos Aires: Emece.

Mata, M. C. (1993). La radio: una relación comunicativa. Diálogos de la Comunicación, 35, 10-13.

Mata, M. C. (2006). Comunicación y ciudadanía. Problemas teóricopolíticos de su articulación. Fronteiras-Estudos midiáticos, 8(1), 6-15. Recuperado de http://revistas.unisinos.br/index. $\mathrm{php} /$ fronteiras/article/view/6113/3289

Mata, M. C. (2011). Comunicación popular: continuidades, transformaciones y desafíos. Oficios Terrestres, 1(26), 1-22. Recuperado de https://perio.unlp.edu.ar/ojs/index.php/oficiosterrestres/article/view/982

Montani, R. (2015). El ingenio como superartefacto. Notas para una etnografía histórica de la cultura material wichi. En L. Córdoba, F. Bossert, y N. Richard (Eds.), Capitalismo en las selvas: Enclaves Industriales en el Chaco y Amazonía Indígenas (1850-1950) (pp. 19-44). San Pedro de Atacama: Editorial del Desierto.

Montes Cató, J. y Ventrici, P. (2017). Pérdida de derechos laborales en la restauración neoliberal argentina. Revista de Políticas Públicas, 21(2), 661-679. https://doi.org/10.18764/2178-2865. v21n2p661-680

Naharro, N., Flores Klaric, M., y Kantor, L. (2009). Situación de las comunidades en relación a las distintas formas de tenencia de la tierra. En C. Buliubasich y A. González (Comps.), Los pueblos indígenas de la provincia de Salta. La posesión y el dominio de sus tierras. Departamento San Martín (pp. 59-66). Salta: Cartoon. 
Naharro, N., Flores Klaric, M., Álvarez, A. (2015). Tensiones entre políticas agrarias y derechos indígenas y ambientales. El caso de los agronegocios en Ballivián. En S. Álvarez Leguizamón (Comp.), Neocolonialismo, capitalismo, pobreza y resistencias subalternas (pp. 155-192). Rosario: Prohistoria Argentina.

Operti, R. (2014). Plan estratégico de desarrollo local del Municipio de Tartagal Salta. Salta: Secretaría de Planificación- Gobierno de la Provincia de Salta.

Ortega, M. (2020). La comunicación comunitaria y las estrategias de lucha por los derechos de la naturaleza: análisis del caso de la comunidad Territorios Originarios Wichi. AVATARES de la Comunicación y la Cultura, 19, 1-18. Recuperado de http://ppct. caicyt.gov.ar/index.php/avatares/article/view/16909/pdf

Paulizzi, C. (2013). El estar siendo de la UTD Mosconi. Una aproximación geocultural a la lucha piquetera. Academia Libre y Popular Latinoamericana de Humanidades Memorias Periféricas, 3, 18-25. Recuperado de https://ri.conicet.gov.ar/ handle $/ 11336 / 3148$ ?show=full

Paulizzi, C. (2015). Re-configuración del Estado y re-invención de lo social en la Argentina actual. El gobierno de la pobreza (2003-2012). Trabajo y Sociedad, 24, 183-205. Recuperado de https://www.unse.edu.ar/trabajoysociedad/24\%20Paulizzi\%20Cora\%20Gobierno\%20de\%20la\%20Pobreza.pdf

Paulizzi, C. (2016). Las prácticas de resistencia y autogobierno de la unión de trabajadores desocupados de Gral. MosconiSalta: aproximación crítica. Andes, 27, 1-29. Recuperado de https://www.redalyc.org/pdf/127/12749260001.pdf

Paulizzi, C. y Milana, P. (2015). Los avatares de la gubernamentalidad y la cuestión del Estado. Una aproximación crítica desde el gobierno de la pobreza y las prácticas de resistencia (Salta, Argentina). Astrolabio, 15, 356-386. Recuperado de https://revistas.unc.edu.ar/index.php/astrolabio/article/view/10739

Platero, L. (2012). La interseccionalidad como herramienta de estudio de la sexualidad. En L. Platero (Ed.), Intersecciones: cuerpos y sexualidades en la encrucijada (pp. 15-73) Barcelona: Ediciones Belaterra.

Pojasi, A. (2013). Tartagal, Salta, República Argentina: sus orígenes y demarcación de límites: 1864-1925. Salta: Fondo Editorial Secretaría de Cultura de la provincia de Salta. 
Rioja, L. (1997). Tartagal y el Norte del Bermejo (tierra olvidada). Apuntes, Crónicas y Relatos sobre su Historia y Geografía. Tartagal: 3L Ediciones.

Rose, N. (1997). El gobierno en las democracias liberales avanzadas: del liberalismo al neoliberalismo. Archipiélago, 29, 25-40.

Rose, N. (2007). ¿La muerte de lo social? Reconfiguración del territorio de gobierno. Revista Argentina de Sociología, 5(8), 111-150. Recuperado de https://www.redalyc.org/pdf/269/26950807. pdf

Rose, N., O'Malley, P., y Valverde, M. (2012). Gubernamentalidad. Astrolabio, 8, 113-152. Recuperado de https://revistas.unc.edu. ar/index.php/astrolabio/article/view/2042

Ruidrejo, A. (2019). Las misiones jesuíticas del Paraguay. Neoliberalismo y poder pastoral. En A. Avellaneda y G. Vega (Comp.), Conductas que importan. Variantes de análisis de los estudios en gubernamentalidad (pp. 371-403). Corrientes: Editorial de la Universidad del Nordeste, EUDENE.

Rutledge, I. (1987). Cambio agrario e integración. El desarrollo del capitalismo en Jujuy: 1550-1960. San Miguel de Tucumán: Cooperativa de Trabajadores Gráficos de Tucumán, COOTGRATUC.

Sacchi, E. (2017). Neoliberalismo, gubernamentalidad y mnemotécnicas de la crueldad. El Arco y la Lira. Tensiones y Debates, 5, 47-63. Recuperado de https://ri.conicet.gov.ar/handle/11336/68628

Santamaría, D. J. (2008). Esclavos en el paraíso. Misioneros franciscanos en los pedemontes andinos. San Salvador de Jujuy: Purmamarka.

Scott, D. (2005). Gubernamentalidad colonial. En X. Inda (Ed.), Antropologías de la modernidad. Foucault, gubernamentalidad y políticas de la vida (pp. 23-50). Londres: Blackwell Publishing.

Shore, C. (2010). La Antropología y el Estudio de la Política Pública: Reflexiones Sobre la "Formulación" de las Políticas. Antípoda. Revista de Antropología y Arqueología (10), 21-49. Recuperado de https://www.redalyc.org/pdf/814/81415652003.pdf

Svampa, M. (2003). Organizaciones de trabajadores desocupados. El modelo de General Mosconi. En I. González Bombal (Comp.), Nuevos movimientos sociales y ONGs en la Argenti- 
na de la crisis (pp. 52-78). Buenos Aires: Centro de Estudios de Estado y Sociedad.

Szlechter, D., Vanegas, J., y Tijonchuk, A. (2018). Representaciones de la meritocracia en la prensa escrita argentina a partir de la asunción de Macri. Psicoperspectivas. Individuo y Sociedad, 17(3), 1-12. https://doi.org/10.5027/psicoperspectivasvol17-issue3-fulltext-1359

Teruel, A. (1995). Introducción, notas y selección de textos. En P. Pellichi, J. Remedi, P. Iturralde, y R. Gobelli (Eds.), Misioneros del Chaco Occidental. Escritos de Franciscanos del Chaco Salteño (1861-1914) (pp. 8-12). San Salvador de Jujuy: Centro de Estudios Indígenas y Coloniales Departamento Editorial.

Teruel, A. (2005). Misiones economía y sociedad. La frontera chaqueña del noroeste argentino en el siglo XX. Quilmes: Editorial Universidad Nacional de Quilmes.

Thuar, A. (1997). A través del Gran Chaco 1883-1887. La Paz: Editorial Los Amigos del Libro.

Trinchero, H. y Valverde, S. (2014). De la "guerra con el indio" a los pueblos originarios como sujetos sociales y políticos: del Centenario al Bicentenario argentino. En H. Trinchero y S. Valverde (Comp.), Pueblos indígenas, estados nacionales y fronteras: tensiones y paradojas de los procesos de transición contemporáneos en América Latina (pp. 175-222). Buenos Aires: Editorial de la Facultad de la Facultad de Filosofía y Letras Universidad de Buenos Aires.

Vinelli, N. (2014). Comunicación alternativa: Ni dogma ni pureza, conflicto. En Nuevas configuraciones de la cultura en lenguaje, representaciones y relatos. Ponencia presentada en XVI Congreso REDCOM Red de Carreras de Comunicación Social y Periodismo de Argentina, La Plata, Argentina.

Vommaro, G. y Gené, M. (2017). Argentina: el año de CAMBIEMOS. Revista de Ciencia Política, 37(2), 231-253. https://doi. org/10.4067/s0718-090x2017000200231 